\title{
Loss of Object Recognition Memory Produced by Extended Access to Methamphetamine Self-Administration is Reversed by Positive Allosteric Modulation of Metabotropic Glutamate Receptor 5
}

\author{
Carmela M Reichel', Marek Schwendt', Jacqueline F McGinty', M Foster Olive' and Ronald E See ${ }^{*, \prime}$ \\ 'Department of Neurosciences, Medical University of South Carolina, Charleston, SC, USA
}

\begin{abstract}
Chronic methamphetamine (meth) abuse can lead to persisting cognitive deficits. Here, we utilized a long-access meth self-administration (SA) protocol to assess recognition memory and metabotropic glutamate receptor (mGluR) expression, and the possible reversal of cognitive impairments with the mGluR5 allosteric modulator, 3-cyano- $\mathrm{N}$-(I,3-diphenyl-|H-pyrazol-5-yl) benzamide (CDPPB). Male, Long-Evans rats self-administered i.v. meth $(0.02 \mathrm{mg}$ /infusion) on an FRI schedule of reinforcement or received yoked-saline infusions. After seven daily I-h sessions, rats were switched to 6-h daily sessions for 14 days, and then underwent drug abstinence. Rats were tested for object recognition memory at I week after meth SA at 90 min and $24 \mathrm{~h}$ retention intervals. In a separate experiment, rats underwent the same protocol, but received either vehicle or CDPPB (30 mg/kg) after familiarization. Rats were killed on day 8 or 14 post-SA and brain tissue was obtained. Meth intake escalated over the extended access period. Additionally, meth-experienced rats showed deficits in both short- and long-term recognition memory, demonstrated by a lack of novel object exploration. The deficit at 90 min was reversed by CDPPB treatment. On day 8, meth intake during SA negatively correlated with mGluR expression in the perirhinal and prefrontal cortex, and mGluR5 receptor expression was decreased 14 days after discontinuation of meth. This effect was specific to mGluR5 levels in the perirhinal cortex, as no differences were identified in the hippocampus or in mGluR2/3 receptors. These results from a clinically-relevant animal model of addiction suggest that mGluR5 receptor modulation may be a potential treatment of cognitive dysfunction in meth addiction.
\end{abstract}

Neuropsychopharmacology (201 I) 36, 782-792; doi:I0.1038/npp.2010.212; published online 8 December 2010

Keywords: glutamate; metabotropic; methamphetamine; object memory; rat; self-administration

\section{INTRODUCTION}

Methamphetamine (meth) addiction is a chronically relapsing disorder that can induce psychiatric symptoms and cognitive impairments. Clinical data reveal that long-term meth users exhibit deficits in specific cognitive domains, with memory tasks among the most pronounced (Scott et al, 2007). For example, deficits have been demonstrated on tests of verbal (Hoffman et al, 2006), working (Gonzalez et al, 2007), prospective (Rendell et al, 2009), and episodic memory (Simon et al, 2004). These deficits coincide with meth-related changes in the cortical metabolites

*Correspondence: Dr RE See, Department of Neurosciences, Medical University of South Carolina, 173 Ashley Avenue, BSB 4I6B, Charleston SC 29425, USA, Tel: + I 843792 2487, Fax: + I 843792 4423,

E-mail: seere@musc.edu

Received 7 September 2010; revised 6 November 2010; accepted 8 November 2010
$\mathrm{N}$-acetylaspartate, creatine, phosphocreatine, and choline (Chang et al, 2007; Salo et al, 2007), decreased frontal cortical activation (Paulus et al, 2003), reductions in dopamine transporter availability (Volkow et al, 2001a,b), and downregulation of the glutamate/glutamine (GLX) system in clinical populations (Ernst and Chang, 2008). Although some cognitive and neuronal deficits appear to recover with time (Ernst and Chang, 2008; Salo et al, 2009; Volkow et al, 2001a), memory deficits may have a crucial role in adherence to treatment protocols.

In preclinical rodent models, some components of episodic memory can be evaluated by an object recognition task (Ennaceur, 2010). Object recognition tasks are based on the natural tendency of rodents to spend more time interacting with novel relative to familiar objects (Berlyne, 1950) and provide a one-trial recognition memory task that does not involve heuristic learning or changes in motivational state (Ennaceur and Delacour, 1988). Experimenter-delivered meth impairs recognition memory 
under multiple dosing conditions (Belcher et al, 2005, 2006, 2008; Bisagno et al, 2002; Schröder et al, 2003). However, these studies deliver acute high meth doses in a manner unlike that experienced by human addicts. Extended daily self-administration (SA) paradigms are considered to provide clinically relevant approaches for modeling addiction because they rely on response-contingent drug delivery and are often characterized by an escalation of drug intake reminiscent of human drug taking (Ahmed and Koob, 1999; Ahmed et al, 2000; Kitamura et al, 2006). Recently, our laboratory reported that extended access to meth SA increased meth intake, enhanced reinstatement of drugseeking after a meth-priming injection, and impaired novel object recognition (Rogers et al, 2008; Schwendt et al, 2009). The deficit in novel object recognition was dependent on cumulative daily meth access period $(1,2$, or $6 \mathrm{~h}$ per day), with only $6 \mathrm{~h}$ per day, animals showing significant deficits relative to yoked-saline controls.

Fast acting ionotropic glutamate receptors in the perirhinal cortex are thought to mediate the acquisition, consolidation, and retrieval of recognition memory (Winters and Bussey, 2005). In fact, blockade of $N$-methyl-D-aspartate (NMDA) receptors in the perirhinal cortex before sampling objects impaired object recognition at 1 and $24 \mathrm{~h}$ intervals (Barker GR et al, 2006; Barker GRI et al, 2006; Barker and Warburton, 2008). However, the less-studied metabotropic glutamate receptors (mGluR) also have a role in recognition memory. For example, systemic administration of mGluR antagonists (mGluR2/3 and five subtypes) before sampling novel objects and before testing impaired short and longterm recognition memory (Barker GR et al, 2006; Barker GRI et al, 2006; Christoffersen et al, 2008). Additionally, stimulation of mGluR5 with the positive allosteric modulator, 3-cyano- $N$-(1,3-diphenyl-1H-pyrazol-5-yl) benzamide (CDPPB), enhanced recognition memory in normal rats (Uslaner et al, 2009) and facilitated spatial memory in mice (Ayala et al, 2009).

Therefore, in this study, we first determined whether extended access to SA meth, a translationally relevant regimen with cognitive and motivational consequences, interferes with recognition memory using a well-characterized one-trial memory task. Further, we extracted brain areas associated with recognition memory at a time point well after meth SA (two weeks) in order to examine potential changes in mGluR levels during abstinence. This time point is consistent with previous noncontingent meth binge, escalation, and sensitization regimens that have tested recognition memory on days 7 and 8 , followed by neurochemical analysis at 14 days after meth (Belcher et al, $2005,2006,2008$ ). As we observed a decrease in mGluR5 levels in the perirhinal cortex in meth SA rats relative to yoked-saline rats, in a subsequent experiment we tested whether positive allosteric modulation of mGluR5 would reverse the meth-induced memory deficit and alter receptor expression shortly after object recognition behavior was assessed. Although the prefrontal cortex is not traditionally considered part of object recognition circuitry (Barker et al, 2007; Ennaceur et al, 1997; Mitchell and Laiacona, 1998; Warburton and Brown, 2010), some evidence suggests involvement of prefrontal mGluR5 receptors (Christoffersen et al, 2008). As such, the perirhinal cortex, prefrontal cortex, and hippocampus were collected. These assessments of meth-induced memory impairments and the subsequent pharmacological reversal may provide insight on the possible mechanisms involved in recognition memory deficits following meth SA.

\section{MATERIALS AND METHODS}

\section{Subjects}

A total of 63 male Long-Evans rats (Charles-River) weighing 250-300 g were individually housed on a reversed 12:12 light-dark cycle. Rats received ad libitum water and standard rat chow (Harlan, Indianapolis, IN), except during initial acquisition of SA, when they received $25 \mathrm{~g}$ per day. Procedures were conducted in accordance with the 'Guide for the Care and Use of Laboratory Rats' (Institute of Laboratory Animal Resources on Life Sciences, National Research Council) and approved by the IACUC of the Medical University of South Carolina.

\section{Surgery}

Rats were anesthetized with i.p. ketamine $(66 \mathrm{mg} / \mathrm{kg}$ ), xylazine $(1.3 \mathrm{mg} / \mathrm{kg})$, and equithesin $(0.5 \mathrm{ml} / \mathrm{kg}$. Ketorolac $(2.0 \mathrm{mg} / \mathrm{kg})$ was administered preoperatively for analgesia. One end of a silastic catheter was inserted into the external right jugular and secured with 4.0 silk sutures. The other end ran subcutaneously and exited from a small incision just between the scapula and attached to an infusion harness (Instech Solomon, Plymouth Meeting, PA) that provided access to an external port for i.v. drug delivery. The antibiotic, cefazolin $(10 \mathrm{mg} / 0.1 \mathrm{ml})$, was infused postsurgery and during recovery with $0.1 \mathrm{ml} 70 \mathrm{U} / \mathrm{ml}$ heparinized saline. During SA, rats received an infusion $(0.1 \mathrm{ml})$ of $10 \mathrm{U} / \mathrm{ml}$ heparinized-saline before each session. After each session, catheters were flushed with cefazolin and $0.1 \mathrm{ml} \mathrm{70} \mathrm{U/ml} \mathrm{heparinized} \mathrm{saline.} \mathrm{Catheter} \mathrm{patency} \mathrm{was}$ verified by periodic infusions of methohexital sodium $(10 \mathrm{mg} / \mathrm{ml}$ in $0.9 \% \mathrm{NaCl})$, a short-acting barbiturate that produces a rapid loss of muscle tone when administered i.v.

\section{Meth SA}

SA occurred in chambers $\left(30 \times 20 \times 20 \mathrm{~cm}^{3}\right.$, Med Associates, St Albans, VT) housed inside sound-attenuating cubicles fitted with a fan, metal arm, and spring leash attached to a swivel (Instech), two retractable levers, two stimulus lights, a speaker for tone delivery, and a house light. Tygon tubing extended through the leash and connected to a $10 \mathrm{ml}$ syringe mounted on an infusion pump outside the cubicle. After 5 days of recovery, rats were assigned to meth or yoked-saline control groups. Meth hydrochloride (Sigma, St Louis, MO), dissolved in sterile saline, was administered daily during 1 -h sessions for 7 days on an FR1 schedule of reinforcement, followed by 6-h sessions for 14 days (Figures 1a and 2a). The house light signaled the beginning of a session and remained on throughout the session. A response on the active lever resulted in a 2 -s infusion $(20 \mu \mathrm{g} / 50 \mu \mathrm{l}$ bolus), and presentation of a stimulus complex consisting of a 5 -s tone $(78 \mathrm{~dB}$, $4.5 \mathrm{kHz}$ ) and a white stimulus light over the active lever, followed by a 20 -s time-out. Responses during the time-out 

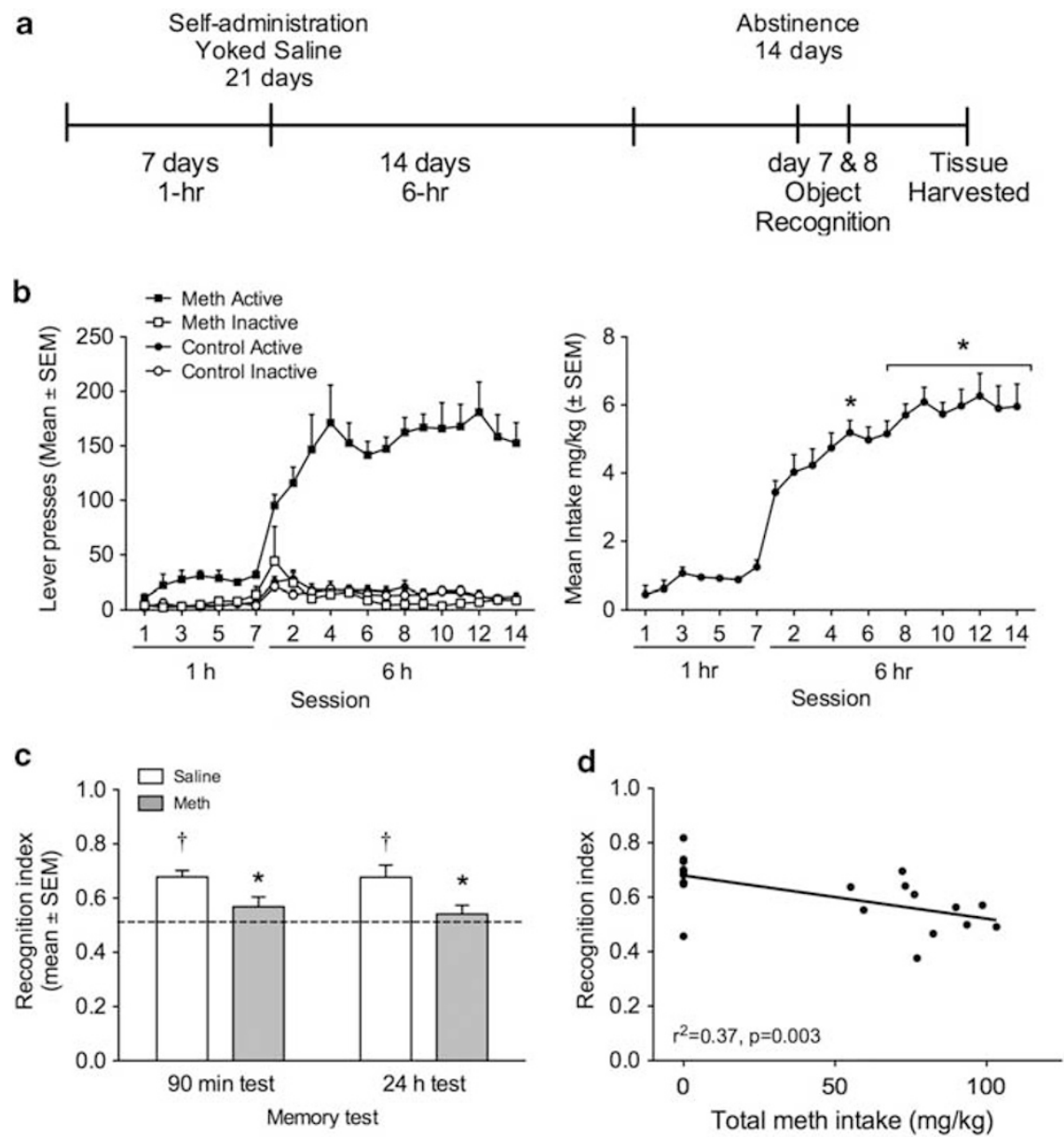

Figure I Self-administration and object recognition data from Experiment I. (a) Time course for Experiment I. Recognition memory was tested on days 7 and 8 of abstinence and tissue was collected on day 14. (b) Lever responding (left graph) and meth intake (right graph) during chronic meth SA and yokedsaline controls. Significant differences from first day of long access are indicated $(* p<0.05)$. (c) Object exploration for rats with a history of chronic meth SA (gray bars) and yoked-saline controls (white bars) at the 90 - $\mathrm{min}$ and $24 \mathrm{~h}$ test sessions. Data are represented as an index between time spent exploring a novel object/time with both objects. Significant differences from chance exploration ( $p<0.05$ ) or control (* $p<0.05)$ are indicated. (d) Scatter plot and correlation value representing the relationship between meth intake during chronic meth SA and object recognition.

and on the inactive lever were recorded, but had no scheduled consequences. Yoked controls received a $50 \mu \mathrm{l}$ saline infusion whenever the matched subject received a meth infusion.

\section{Novel Object Recognition}

During abstinence, rats were handled daily, but never returned to the SA chamber. On days 5 and 6 , rats were habituated to the apparatus for $5 \mathrm{~min}$ without objects. During familiarization, rats explored two identical objects for 3 min (day 7 abstinence). A short-term memory test was conducted $90 \mathrm{~min}$ later by allowing rats to explore an object from the familiarization phase and a novel object for $3 \mathrm{~min}$. A long-term test was conducted $24 \mathrm{~h}$ after sampling (day 8 abstinence), in which rats were given the familiar object and a different novel object. Both familiar $v s$ novel objects and object placement were counterbalanced. The objects used were on the basis of preliminary research with naive rats demonstrating that the objects engendered similar exploration and consisted of combinations of a white sock $\left(7.5 \times 7.5 \mathrm{~cm}^{2}\right)$, a PVC pipe $\left(6.4 \times 3.8 \mathrm{~cm}^{2}\right)$, a plastic scouring pad $(9 \mathrm{~cm}$ diameter), a paint roller $\left(7.5 \times 2.5 \mathrm{~cm}^{2}\right)$, a light bulb $(8.9 \mathrm{~cm})$, and a tennis ball (adapted from Bevins et al, 2002). Object exploration was defined as sniffing or touching the object with the nose but not sitting, leaning, or standing on the object. All objects and the apparatus were wiped down with $70 \%$ isopropyl alcohol between sessions.

\section{Tissue Extraction and Western Blotting}

Rats were rapidly euthanized on day 8 or 14 of abstinence; brains were removed and chilled on ice. Regions of interest (Supplementary Figure S1, Supplementary Materials and Methods) were dissected from $2 \mathrm{~mm}$ thick coronal slices obtained using a rat brain slicer (Braintree Scientific, MA). Tissues were processed for crude membrane (P2) fractions and stored at $-80^{\circ} \mathrm{C}$ until further processing. Samples were solubilized in $1 \%$ SDS/phosphate-buffered saline containing protease and phosphatase inhibitors (Complete Mini protease inhibitor; Roche Diagnostics, Indianapolis, IN) and a Halt phosphatase inhibitor (Thermo Fisher Scientific, Rockford, IL). Equal amounts of protein $(10 \mu \mathrm{g})$ were resolved using SDS-PAGE (4-15\%) and transferred to 
a

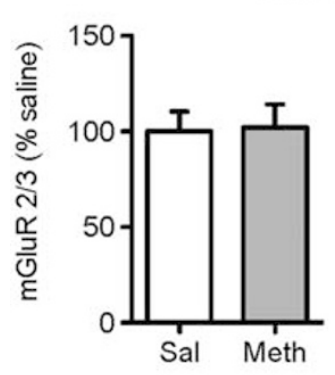

Hippocampus day 14

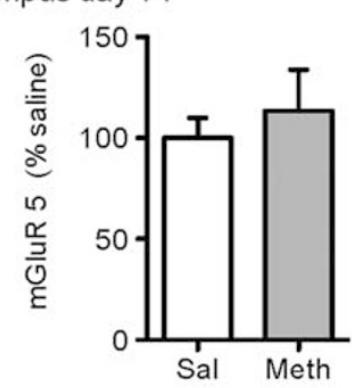

$220 \mathrm{kd}$

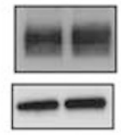

dimer

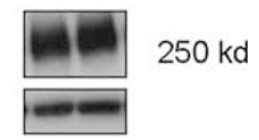

b

calnexin $90 \mathrm{kd}$

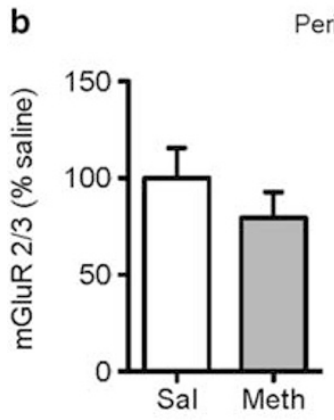

Perirhinal cortex day 14

$220 \mathrm{kd}$
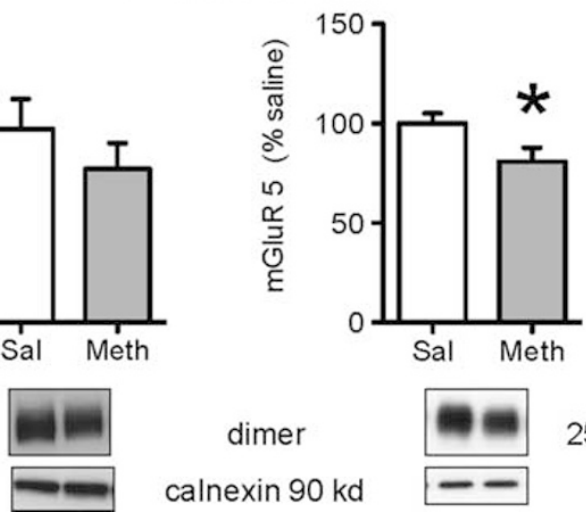

$250 \mathrm{kd}$

Figure 2 mGluR5 and mGluR2/3 protein levels in (a) hippocampus and (b) perirhinal cortex in animals with a history of chronic meth SA and yoked-saline controls. Representative immunoblots depict immunoreactivity of mGluRs in crude P2 membrane fractions. mGluR immunoreactivity was normalized to calnexin and expressed as a percentage of yoked-saline control \pm SEM (*p $<0.05$; significant difference from control).

PVDF membrane (BioRad, Hercules, CA) under either nonreducing or reducing conditions. Under non-reducing conditions, mGluR2/3 and mGluR5 migrate as a single high-molecular weight band corresponding to a receptor dimer (Copani et al, 2000). Addition of $20 \mathrm{mM}$ DTT resulted in a partial reduction of mGluR5 dimers into monomers, without affecting mGluR2/3 dimer state. As it is believed that the dimer form is the functional form of the mGluRs (Pin et al, 2003), mGluR5 receptor levels were analyzed under non-reducing conditions. The membrane was blocked with $5 \% \mathrm{w} / \mathrm{v}$ powdered milk/Tris-buffered saline/Tween-20, and probed with rabbit antibodies for mGluR5 at $1: 10000$ or mGluR2/3 at $1: 10000$ overnight at $4{ }^{\circ} \mathrm{C}$ (Millipore, Billerica, MA). After washing, the membranes were incubated with goat anti-rabbit antiserum $(1: 10000)$ at room temperature, followed by washing with Tris-buffered saline/Tween $(3 \times 10 \mathrm{~min})$. Protein signal was detected using enhanced chemiluminescence plus (Amersham Biosciences, Piscataway, NJ). Equal loading and transfer of proteins were confirmed by probing with anti-calnexin antiserum (Enzo Life Sciences Plymouth Meeting, PA). Samples were assayed in duplicate and matched controls run on each gel. Integrated density of the bands was measured with Image J software (National Institute of Health, Bethesda, MD).

\section{Experimental Procedures}

Experiment 1: meth-induced deficits in recognition memory and mGluR expression in perirhinal cortex and hippocampus. Rats $(n=21)$ underwent SA, followed by object recognition testing using a gray painted wooden box $\left(40 \times 40 \times 38 \mathrm{~cm}^{3}\right)$. Object recognition was recorded and stored with Noldus tracking software (EthoVision XT 6.0, Leesburg, VA) and an observer naive to the experimental conditions manually scored behavior. The perirhinal cortex and hippocampus were collected on the 14th day of abstinence from meth SA.

Experiment 2: $C D P P B$ reversal of meth-induced deficits in recognition memory. Rats $(n=43)$ underwent $\mathrm{SA}$, followed by object recognition testing on a round wooden open field (125 cm diameter, $1.5 \mathrm{~cm}$ thickness, $65 \mathrm{~cm}$ above the floor) painted gray. This change in testing apparatus was used to accommodate a software upgrade that provided additional measures of approach and activity during the sessions. Object recognition was recorded, stored, and scored with the event recorder of Noldus tracking software (EthoVision $\mathrm{XT}$ 7.0). Object recognition testing occurred as before, except that rats received vehicle or CDPPB $(30 \mathrm{mg} / \mathrm{kg})$ immediately after familiarization. This dose of CDPPB reversed MK-801-induced attentional deficits (Stefani and Moghaddam, 2010). CDPPB, synthesized by IQsynthesis (St Louis, MO), was suspended in $0.5 \%$ methylcellulose and injected SC at a volume of $2 \mathrm{ml} / \mathrm{kg}$. Four distinct groups were tested: saline/vehicle, saline/CDPPB, meth/vehicle, and meth/CDPPB (the meth groups were balanced according to SA intake). Rats were rapidly decapitated and brains removed immediately after the $24 \mathrm{~h}$ test on the 8 th day of abstinence from meth.

\section{Statistical Analyses and Behavioral Observations}

Meth intake $(\mathrm{mg} / \mathrm{kg})$ was the primary dependent measure for SA and analyzed with a repeated measures analysis of variance (ANOVA) over the 14 days of long access. Time spent with each object was the primary dependent measure during object recognition testing. Data were converted to a recognition index (novel object exploration/novel object + familiar object exploration). To demonstrate that object recognition occurred for each group, the recognition index was compared with a hypothetical mean of 0.5 using independent $t$-tests. A recognition index of 0.5 indicates equal time spent exploring both objects, greater than 0.5 indicates more exploration of the novel object, and less than 0.5 indicates more exploration of the familiar object. Between-group comparisons were conducted using ANOVA. Western blot data, represented by band density values, were normalized using calnexin band immunoreactivity for the same sample, expressed as a percent of yoked saline control, and analyzed by ANOVA. Pearson product-moment correlation coefficient $(r)$ was used to assess the degree of association between meth intake with mGluR expression and object recognition. A mean recognition index was calculated from both tests for these correlations. Post hoc comparisons consisted of Tukey HSD tests. Statistical analysis was conducted with the alpha set at 0.05 , and all data are expressed as the mean \pm SEM. 


\section{RESULTS}

\section{Experiment 1: Meth-Induced Deficits in Recognition Memory and mGluR Expression in Perirhinal Cortex and Hippocampus}

Meth SA. Figure $1 \mathrm{~b}$ shows lever responding and meth intake $(\mathrm{mg} / \mathrm{kg})$. Yoked-saline rats indiscriminately displayed low levels of responding on both levers. Meth rats showed a distinction between active and inactive lever responding throughout the first 7 days of 1-h access, which was even more pronounced during the 14 days of 6-h access. Escalation of meth intake occurred rapidly. Specifically, over the 14 days of long-access sessions, meth intake on day 5 and days 7-14 was higher than on the first day of long access $(F(13,130)=7.03, p<0.001$; Tukey HSD, $p<0.05)$. Cumulative meth intake during SA ranged from $55.15-103.28 \mathrm{mg} / \mathrm{kg}$.

Object recognition. At 1 week after meth access discontinued, rats were tested for recognition memory. During familiarization, yoked-saline $(0.52 \pm 0.06)$ and meth $(0.55 \pm$ $0.03)$ rats had similar exploration values $(t<1, N S)$, and neither of these values was significantly above $0.5(t s<1.6$, $\mathrm{NS}$ ), indicating equal exploration of both objects. Figure 1c shows the comparisons between the long-access meth group and yoked-saline control group. Only control rats displayed object recognition memory, with significantly higher recognition scores on the $90 \mathrm{~min}(t(9)=7.45, p<0.0001)$ and $24 \mathrm{~h}(t(9)=3.97, p<0.005)$ tests relative to the hypothetical mean of 0.5 . In contrast, meth rats did not differ from the hypothetical means on either test, indicating a lack of recognition memory $(t s<1.8, \mathrm{NS})$. When directly compared, control rats had significantly higher recognition indices than meth rats at both $90 \mathrm{~min}(t(19)=2.47$, $p<0.05)$ and $24 \mathrm{~h}(t(19)=2.5, p<0.05)$. Additionally, Figure 1d depicts a negative correlation between meth intake and recognition index $\left(r^{2}=0.37, p<0.003\right)$.

$m G l u R$ expression. Figure 2 shows $m$ GluR $2 / 3$ and -5 expression in the hippocampus and perirhinal cortex of yoked-saline and long access meth SA rats on abstinence day 14. All data were normalized to calnexin and expressed as the percentage of the yoked-saline control. In the hippocampus, there were no differences between saline and meth rats in mGluR2/3 or mGluR5 expression $(t s<1$, NS). Likewise, mGluR2/3 expression did not differ in the perirhinal cortex $(t s<1, \mathrm{NS})$; however, mGluR5 was significantly reduced in meth rats relative to saline controls $(t(17)=2.18, p<0.05)$. Furthermore, rats $(n=4)$ with the highest meth intake (ie, top quartile) had a $23 \%$ decrease in mGluR5 relative to controls $(t(11)=2.52, p<0.05)$, an effect not evident with perirhinal cortex mGluR2/3 levels.

\section{Experiment 2: CDPPB Reversal of Meth-Induced Deficits in Recognition Memory}

Meth SA. Figure 3b shows lever responding and meth intake $(\mathrm{mg} / \mathrm{kg})$. Similar to experiment 1 , meth rats showed escalated meth intake. Specifically, over the 14 days of longaccess sessions, meth intake on days 10,11 , and 14 was higher than the first day of long access $(F(13,234)=5.96$, $p<0.001$; Tukey HSD, $p<0.05)$. Cumulative meth intake ranged from $25.96-97.08 \mathrm{mg} / \mathrm{kg}$ over the SA period. Yokedsaline rats indiscriminately displayed low levels of responding on both levers.

Object recognition reversal with $C D P P B$. In Experiment 2, yoked-saline and meth rats did not differ in exploration values (saline $=0.46 \pm 0.04$; meth $=0.48 \pm 0.04$ ), approaches to objects (saline $=0.5 \pm 0.03$; meth $=0.49 \pm 0.04$ ), and activity (saline $=3749.19 \pm 522.82$; meth $=4191.26 \pm 910.36$ ) during the familiarization sessions $(t s<1$, NS). Further, exploration values did not differ from $0.5(t s<1$, NS), indicating equal exploration of both objects.

Figure $3 \mathrm{c}$ shows that on the 90-min test, object exploration values were significantly above the hypothetical mean of 0.5 for rats in the saline/vehicle group $(t(10)=4.05, p<0.005)$. However, just as in experiment 1 , rats with a history of meth SA (meth/vehicle) did not exhibit object exploration $(t<1, \mathrm{NS})$. Notably, CDPPB treatment prevented this deficit, as the meth/CDPPB group showed a significantly increased recognition index $(t(9)=3.3$, $p<0.01)$, as did the saline/CDPPB group $(t(11)=8.95$, $p<0.001)$. Comparison of recognition index scores across groups showed that the meth/vehicle group performance was significantly less than the other three groups $(F(3,39)=6.69, p<0.001$; Tukey HSD, $p<0.05)$. The groups did not differ in approach to the objects or activity during the test (Table 1).

Figure $3 \mathrm{~d}$ shows that on the 24 -h test, object exploration values were significantly above the hypothetical mean of 0.5 for rats in the saline/vehicle $(t(10)=3.27, p<0.01)$ and saline/CDPPB $(t(11)=3.65, p<0.005)$ groups. However, both the meth/vehicle $(t<1.7, \mathrm{NS})$ and meth/CDPPB groups $(t<1, \mathrm{NS})$ did not exhibit object exploration, as their values were not significantly above 0.5 . When directly compared, the meth/CDPPB group had a recognition index significantly less than the saline/vehicle and saline/CDPPB groups $(F(3,39)=3.49, p<0.05$; Tukey HSD, $p<0.05)$. The groups did not differ in approach to the objects or activity during the test at the 24-h time-point (Table 1). Additionally, Figure $3 \mathrm{e}$ depicts the negative correlation between meth intake and recognition index $\left(r^{2}=0.28, \mathrm{p}<0.013\right)$ for rats in the saline/veh and meth/veh groups.

mGluR expression. Table 2 shows that mGluR2/3 and -5 receptor expression levels did not differ in the hippocampus, perirhinal, and prefrontal cortex of yoked-saline and long access meth-SA rats on abstinence day 8. In light of the pronounced range in meth intake (25.96$97.08 \mathrm{mg} / \mathrm{kg}$ ), we analyzed the correlations between meth intake and mGluR expression (Figure 4). Meth intake was negatively correlated with mGluR5 levels in both the perirhinal and prefrontal cortices (perirhinal, $r^{2}=0.47$, $p<0.002$; prefrontal, $\left.r^{2}=0.24, p<0.05\right)$, but no such correlation was seen with mGluR2/3-expression levels. In the hippocampus, total meth intake did not correlate with either mGluR2/3 or mGluR5 expression. Additionally, when considering only those rats $(n=5)$ with the highest meth intake (ie, top quartile), mGluR5 levels were decreased relative to control by $17.6 \%$ in the perirhinal cortex $(t(12)=2.75, p<0.05)$, and $23 \%$ in the prefrontal cortex $(t(13)=2.95, p<0.05)$, an effect not evident with perirhinal cortex mGluR2/3. 

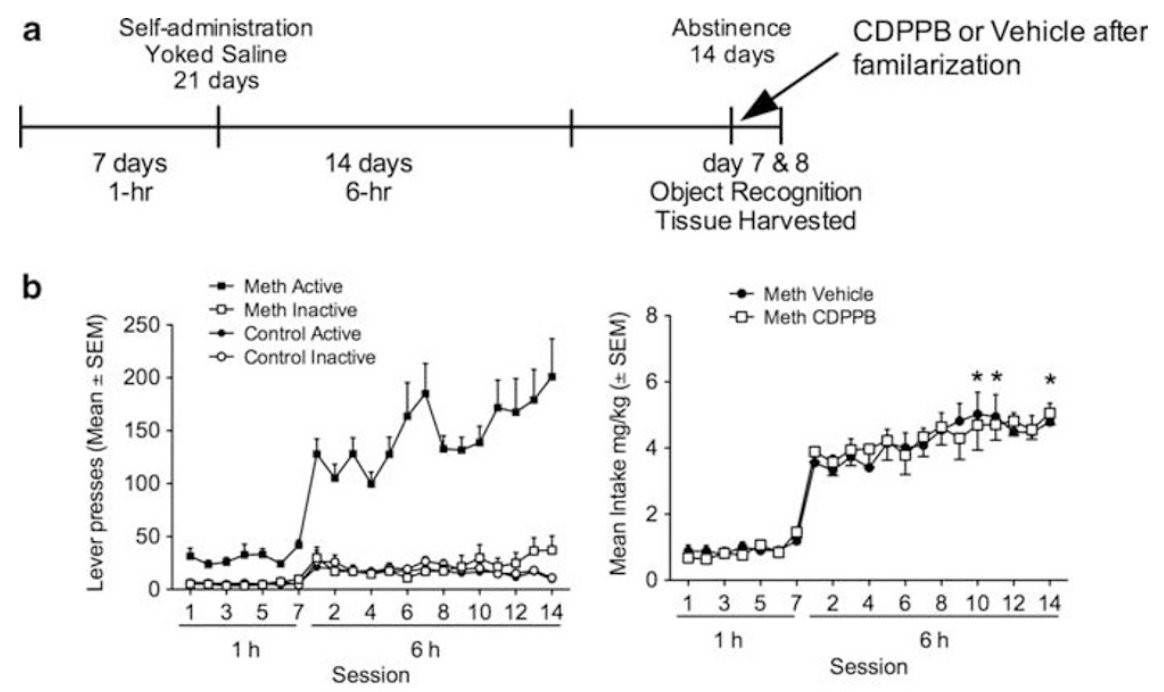

\section{C}

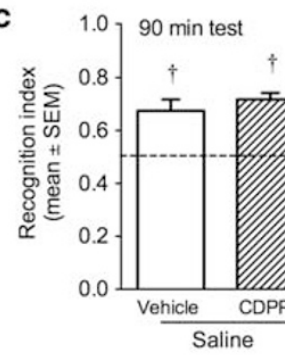

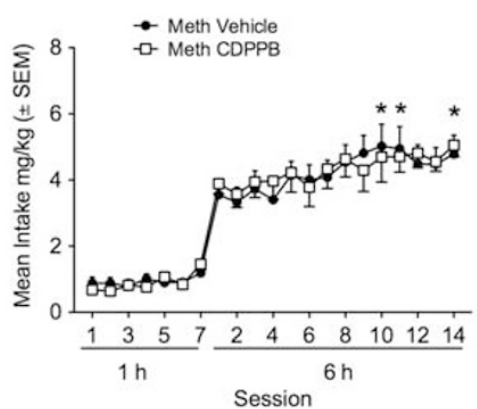

d $\quad 1.0,24 \mathrm{~h}$ test

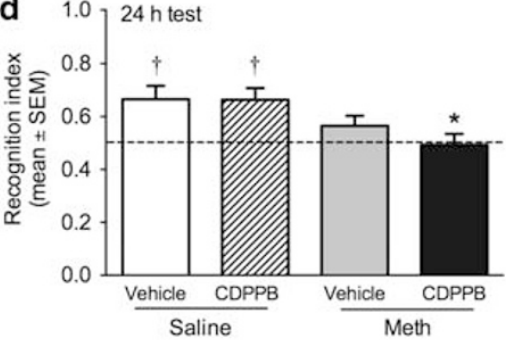

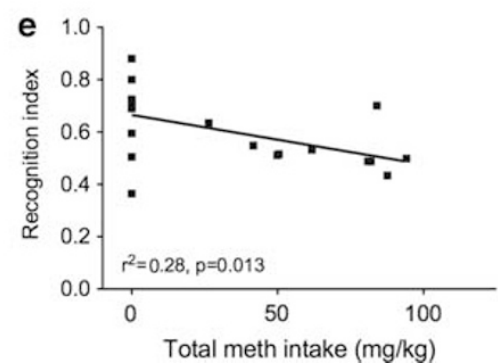

Figure 3 Self-administration and object recognition data from Experiment 2. (a) Time course for Experiment 2. (b) Lever responding (left) and meth intake (right) during chronic meth SA and yoked-saline controls for Experiment 2. Significant differences from the first day of long access are indicated $(* 0<0.05)$. (c and d) Object exploration for rats with a history of chronic meth SA and yoked-saline controls treated with CDPPB or vehicle at the 90 min and $24 \mathrm{~h}$ test sessions. Data are represented as an index between time spent exploring a novel object/time with both objects. Significant differences from chance exploration $\left({ }^{\dagger} p<0.05\right)$ or control $(* p<0.05)$ are indicated. (e) Scatter plot and correlation value representing the relationship between meth intake during chronic meth SA and object recognition.

\section{DISCUSSION}

In this study, chronic meth SA caused a pronounced object recognition memory deficit that was reversed by CDPPB, a positive allosteric modulator of mGluR5. The positive allosteric modulation of mGluR 5 receptors by CDPPB may have compensated for a downregulation of cortical mGluR5 receptors in meth-experienced rats. At 2 weeks after meth SA, mGluR5 levels were decreased $19 \%$ relative to controls in the perirhinal cortex. Furthermore, the degree of previous meth intake correlated with receptor expression in the prefrontal and perirhinal cortices 8 days after meth cessation. The meth-induced memory impairments and their reversal by CDPPB suggest that escalated meth SA, akin to the binge use of meth in humans, produces selective alterations in cortical mGluR5 function that underlie the cognitive deficits associated with heavy meth use.
The extended access SA regimen mimics the course of meth addiction in humans more closely than experimenterdelivered meth. The greater clinical relevance of the SA model is because of the contingent delivery of the drug and the escalation of drug intake as demonstrated by significantly higher intake during the final days relative to the first day of extended access (Ahmed and Koob, 1999; Ahmed et al, 2000; Kitamura et al, 2006; Rogers et al, 2008; Schwendt et al, 2009). With regard to recognition memory, both extended access to meth and cocaine produced deficits in recognition memory using other variations of object recognition tests (Briand et al, 2008; Rogers et al, 2008), which are analogous to those reported in human meth addicts (Scott $e t$ al, 2007). In our laboratory, escalated meth intake resulted in persistent decreases in dopamine transporter protein levels in the prefrontal cortex and dorsal striatum; however, markers specific for dopamine 
Table I Index of Approach to Objects (Novel Object/Both Objects) and Open Field Activity (cm) During Object Recognition Testing on Days 7 and 8 of Abstinence from Meth SA

\begin{tabular}{llllll}
\hline \multirow{2}{*}{ Group } & \multicolumn{2}{c}{$\mathbf{9 0} \mathbf{m i n}$} & & \multicolumn{2}{c}{$\mathbf{2 4 h}$} \\
\cline { 2 - 3 } \cline { 5 - 6 } & Approach & Activity & & Approach & Activity \\
\hline Saline/vehicle & $0.52 \pm 0.05$ & $4121 \pm 1242$ & $0.57 \pm 0.05$ & $3145 \pm 479$ \\
Saline/CDPPB & $0.59 \pm 0.04$ & $7643 \pm 1881$ & $0.55 \pm 0.02$ & $3595 \pm 643$ \\
Meth/vehicle & $0.48 \pm 0.032$ & $6484 \pm 1506$ & & $0.57 \pm 0.03$ & $4100 \pm 1267$ \\
Meth/CDPPB & $0.59 \pm 0.04$ & $4974 \pm 678$ & & $0.52 \pm 0.04$ & $3113 \pm 435$ \\
\hline
\end{tabular}

Abbreviation: CDPPB, 3-cyano-N-(I,3-diphenyl-| |H-pyrazol-5-yl) benzamide.

Table 2 mGluR Expression (\% Of Saline/Vehicle Group) Following CDPPB $(30 \mathrm{mg} / \mathrm{kg})$ or Vehicle After 8 Days of Abstinence from Meth SA

\begin{tabular}{lcccc}
\hline Group & $\begin{array}{c}\text { Saline/ } \\
\text { vehicle }\end{array}$ & $\begin{array}{c}\text { Saline/ } \\
\text { CDPPB }\end{array}$ & $\begin{array}{c}\text { Meth/ } \\
\text { vehicle }\end{array}$ & $\begin{array}{c}\text { Meth/ } \\
\text { CDPPB }\end{array}$ \\
\hline $\begin{array}{l}\text { Hippocampus } \\
\text { mGluR2/3 }\end{array}$ & $100.0 \pm 7.2$ & $84.43 \pm 7.2$ & $82.5 \pm 10.5$ & $89.7 \pm 7.5$ \\
mGluR5 & $100.0 \pm 6.3$ & $84.2 \pm 3.6$ & $94.7 \pm 7.4$ & $94.8 \pm 5.8$ \\
& & & & \\
$\begin{array}{l}\text { Perirhinal cortex } \\
\text { mGluR2/3 }\end{array}$ & $100.0 \pm 17.2$ & $97.5 \pm 12.8$ & $97.8 \pm 14.2$ & $98.6 \pm 13.8$ \\
$\begin{array}{l}\text { mGluR5 } \\
\text { 100.0 } \pm 4.2\end{array}$ & $102.3 \pm 7.2$ & $103.0 \pm 6.3$ & $99.2 \pm 10.3$ \\
$\begin{array}{c}\text { Prefrontal cortex } \\
\text { mGluR2/3 }\end{array}$ & $100.0 \pm 8.9$ & $109.0 \pm 12.5$ & $93.8 \pm 10.5$ & $111.1 \pm 11.6$ \\
$\begin{array}{l}\text { mGluR5 } \\
\text { 100.0 }\end{array}$ & $106.3 \pm 9.3$ & $102.8 \pm 10.2$ & $107.9 \pm 6.2$ \\
\hline
\end{tabular}

toxicity or glial cell activation were not impacted (Schwendt et al, 2009). In contrast, a 15 -h per day $\times 8$ days of methSA study reported cortical and striatal reductions in DAT and tyrosine hydroxylase, accompanied by elevated glial fibrillary acidic protein in these regions (Krasnova et al, 2010). Similarly, Sekine et al (2008) demonstrated microglial activation in the brains of human meth users. However, both short $(1 \mathrm{~h})$ and long $(6 \mathrm{~h})$ meth access conditions decreased cell proliferation and survival, and increased cell death in the medial prefrontal cortex (Mandyam et al, 2007). Regardless of the differences between these studies, meth-SA paradigms, particularly long access, are beginning to characterize long-term neurochemical and functional changes in rodents that are suggestive of human meth addiction.

The perirhinal cortex has emerged as one of the primary brain areas involved in encoding, consolidation, and retrieval of recognition memory involving interactions with the hippocampus (Warburton and Brown, 2010; Winters and Bussey, 2005). These areas have dense connections between them, either directly or indirectly through the entorhinal cortex, and have distinct roles in recognition memory (Aggleton and Brown, 2005; Brown and Aggleton, 2001; Ennaceur and Aggleton, 1997; Wan et al, 1999). However, most ablation studies do not find consistent effects of hippocampal lesions on novel object recognition memory, particularly when spatial processing is minimized (Mumby, 2001; Winters et al, 2004), leading to the general consensus that the perirhinal cortex is the primary mediator of object recognition memory. Additionally, both electrophysiological and immunohistochemical studies show that a proportion of perirhinal neurons respond to novel stimuli, and this response is decreased with ensuing exposures (Brown and Aggleton, 2001; Zhu et al, 1995). Indeed, the induction of long-term depression (LTD) in the perirhinal cortex is one mechanism suggested to underlie recognition memory (Cho et al, 2000; Massey and Bashir, 2007).

The perirhinal cortex is of additional importance with regard to meth addiction, as multiple neurotransmitter systems (including serotonin, cannabinoid, and glutamate) are dysregulated in the perirhinal region by meth (Belcher et al, 2005; Belcher et al, 2008; Bortolato et al, 2010). Blockade of NMDA, mGluR2/3, and mGluR5 receptors in the perirhinal cortex before sampling objects impaired object recognition at 24-h intervals (Barker GRI et al, 2006; Barker GR et al, 2006). Interestingly, LTD in the perirhinal cortex requires conjoint activation of both NMDA and mGluRs, rather than other forms of LTD that depend upon specific activation of ionotropic or metabotropic receptors (Cho et al, 2000); hence, meth-induced dysregulation through any of these receptors may prevent the development of LTD, thus blocking recognition memory. Support for this possibility comes from a study in which mGluR5dependent LTD was impaired in rats with a previous history of cocaine SA (Moussawi et al, 2009).

The dysregulation in mGluR5 and not $-2 / 3$ is interesting, as systemic and perirhinal intracortical coadministration of antagonists for both receptor subtypes was required to block acquisition of recognition memory with a $24 \mathrm{~h}$ delay (Barker GR et al, 2006), suggesting that both combined activation of mGluR5-dependent postsynaptic signaling and presynaptic modulation of glutamate release by mGluR $2 / 3$ are important for recognition memory. Given this finding, we expected a decrease in both group I and II mGluRs in the perirhinal cortex. Although the magnitude of reduction was similar between mGluR2/3 and -5 in the perirhinal cortex on abstinence day 14, changes in mGluR2/3 were not significant. Consistently, meth intake did not correlate with mGluR2/3, nor did rats in the upper quartile of meth intake differ from controls in mGluR2/3 expression. Combined, these data suggest that perirhinal mGluR5 receptors may be more sensitive to the effects of chronic meth than mGluR2/3. Although the exact mechanisms responsible for this difference remain to be determined, one possibility is the interaction of mGluR5 with NMDA receptors, given the functional linkage between these receptors (Alagarsamy et al, 1999; Awad et al, 2000; Salt and Binns, 2000) and the importance for both mGluR5 and NMDA in object recognition memory (Barker GR et al, 2006; Barker GRI et al, 2006; Christoffersen et al, 2008; Uslaner et al, 2009).

Excitotoxic lesions of the perirhinal cortex, but not the prefrontal cortex, completely impair object recognition memory (Barker et al, 2007; Ennaceur et al, 1997; Mitchell and Laiacona, 1998; Warburton and Brown, 2010). Further, object recognition memory does not rely upon interactions between the prefrontal and perirhinal cortices (Warburton and Brown, 2010). However, Christoffersen et al (2008) reported that prelimbic cortex infusions of 
Hippocampus
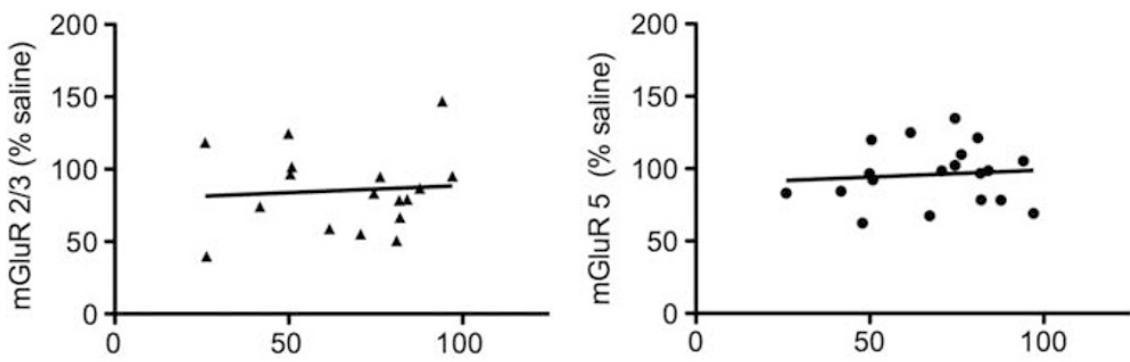

Perirhinal cortex
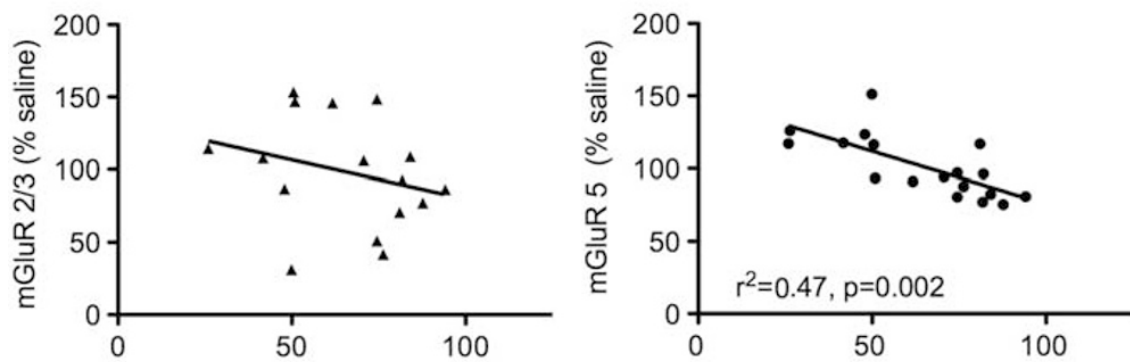

Prefrontal cortex
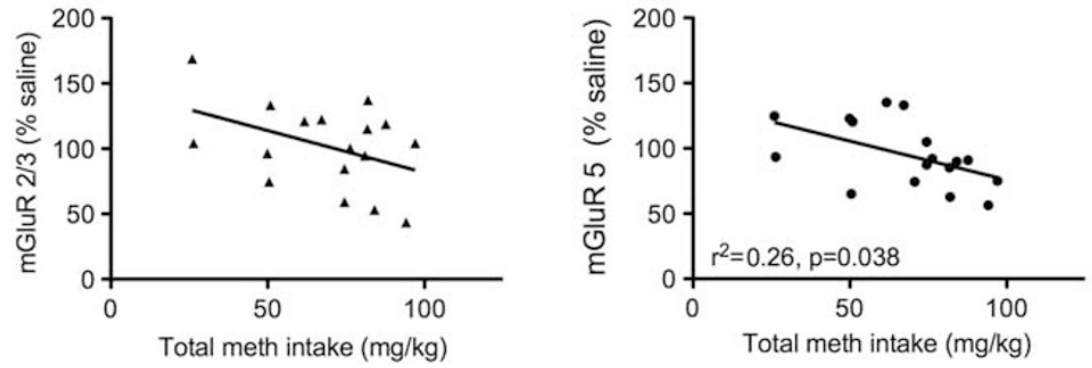

Figure 4 Scatter plots and correlation values representing the relationship between meth intake during chronic meth SA and mGluR expression in the hippocampus, perirhinal cortex, and prefrontal cortex for mGluR 2/3 (left) and mGluR5 (right).

MPEP (an mGluR5 antagonist) blocked recognition memory when the sample to test interval was very short $(5 \mathrm{~min})$. Given this finding and the impact of meth on frontal cortex-mediated cognitive processes, we extended the brain areas investigated in Experiment 2 to include the prefrontal cortex.

Decreased mGluR5 was not readily apparent at 8 days after meth SA, suggesting that longer durations of abstinence from meth may be required for this neuroadaptation to be expressed, as seen with changes ensuing after chronic cocaine (Ghasemzadeh et al, 2009; Grimm et al, 2003; Tran-Nguyen et al, 1998) and meth (Krasnova et al, 2010). However, a closer examination of the data provides a more parsimonious explanation for this finding. When considering rats with the highest meth intake (ie, upper quartile), mGluR5 expression was reduced relative to controls at both abstinence time points (day 8 and 14). Additionally, subjects in the two different experiments exhibited a difference in the range of meth intake, whereby intake in the first experiment ranged from $55.15-103.28 \mathrm{mg} / \mathrm{kg}$, in contrast to $25.96-97.08 \mathrm{mg} / \mathrm{kg}$ in the second experiment. Having the lower end of the continuum provided an opportunity to assess the relationship between meth intake and mGluR expression. As meth intake increased, the expression of mGluR5 decreased in the perirhinal and prefrontal cortices. Importantly, this negative correlation was consistent with the selective mGluR5 decrease in the perirhinal cortex on day 14 of abstinence, in that, such correlations were not apparent with mGluR2/3 or in the hippocampus. Taken together, these data establish a plausible association between meth intake and decrease in cortical mGluR5 at the time of object recognition testing.

Positive allosteric modulators of mGluR5, such as CDPPB, may offer a novel therapeutic approach to treat addiction. These compounds bind to an allosteric site distinct from the orthosteric glutamate-binding site of the mGluR5 (Kinney et al, 2005). Although devoid of any agonistic activity, positive allosteric modulators potentiate the receptor response to endogenously released glutamate (Christopoulos, 2002). Additionally, mGluR5-positive allosteric modulators, such as CDPPB and related compounds, enhance synaptic plasticity (Ayala et al, 2009), improve cognitive function (Liu et al, 2008), facilitate extinction of cocaine-conditioned cues (Gass and Olive, 2009), and decrease extinction responding after cocaine SA (Olive, 2010). In addition to enhancing cognitive function in normal rats, $\mathrm{CDPPB}$ 
reverses amphetamine-induced deficits in prepulse inhibition (Kinney et al, 2005) and MK-801-induced deficits in both object recognition memory (Uslaner et al, 2009) and cognitive flexibility (Darrah et al, 2008; Stefani and Moghaddam, 2010).

The deficit in object recognition memory is not merely a consequence of meth exposure, because rats given 1- or 2-h daily meth SA exposure do not exhibit the same memory deficit (Rogers et al, 2008). Additionally, we have found that rats given 2-h meth SA sessions for 14 days spend more time interacting with novel objects rather than familiar objects, indicating intact recognition memory (unpublished data). However, perirhinal mGluR5-receptor expression has not been assessed in rats with limited access to selfadministered meth (ie, 1- or 2-h sessions), so it remains unknown whether this deficit is specific to chronic extended access conditions.

Meth rats and the yoked controls did not differ on activity, approach to objects, and time spent with objects during familiarization, indicating no a priori group differences that would interfere with acquisition. In this study, CDPPB recovered the meth-induced memory deficit, whereas the drug was active in the central nervous system, but not after clearance of the compound. The first test was conducted $90 \mathrm{~min}$ after injection and only lasted $3 \mathrm{~min}$; thus, the drug was active at this time point as the plasma half-life of the drug is reported to be approximately $4 \mathrm{~h}$ in rats (Kinney et al, 2005). Further, CDPPB did not impact motor activity or approach during this test, indicating that changes in time spent with the objects was not because of activity or motivational changes from CDPPB treatment. The $24 \mathrm{~h}$ test conducted well after clearance of the compound, a time point in which both meth/vehicle and meth/CDPPB groups were impaired in recognition memory and controls (saline/vehicle and saline/CDPPB), had no difficulty discriminating between novel $v s$ familiar objects. CDPPB did not engender greater object recognition in control rats, although in a recent study, CDPPB improved object recognition memory in unimpaired (ie, normal) rats (Uslaner et al, 2009). The similar recognition indices between saline/vehicle and saline/CDPPB rats in this study may be because of the specific objects used to test recognition memory. Specifically, CDPPB may enhance memory if objects have minimal discernable features, but no impact when objects vary on multiple stimulus dimensions, as in this study.

In conclusion, these findings demonstrate that extended meth SA results in memory deficits linked to localized decreases in cortical mGluR5-receptor expression. Further, the meth-induced cognitive impairments can be recovered by positive allosteric modulation of mGluR5 receptors. Future assessment using this translationally relevant model will be particularly beneficial for therapeutic intervention targeted to alleviate the cognitive and motivational deficits observed in meth addiction.

\section{ACKNOWLEDGEMENTS}

This research was supported by NIH grants P20DA022658 (RES), F32DA029344 (CMR), T32DA007288 (CMR), R01DA024355 (MFO), and C06 RR015455. The authors thank Shannon Ghee,
Clifford Chang, Lauren Ramsey, and Stacey Sigmon for technical assistance.

\section{DISCLOSURE}

The authors declare no conflict of interest.

\section{REFERENCES}

Aggleton JP, Brown MW (2005). Contrasting hippocampal and perirhinal cortex function using immediate early gene imaging. Q J Exp Psychol B 58: 218-233.

Ahmed SH, Koob GF (1999). Long-lasting increase in the set point for cocaine self-administration after escalation in rats. Psychopharmacology 146: 303-312.

Ahmed SH, Walker JR, Koob GF (2000). Persistent increase in the motivation to take heroin in rats with a history of drug escalation. Neuropsychopharmacology 22: 413-421.

Alagarsamy S, Marino MJ, Rouse ST, Gereau RW, Heinemann SF, Conn PJ (1999). Activation of NMDA receptors reverses desensitization of mGluR5 in native and recombinant systems. Nat Neurosci 2: 234-240.

Awad H, Hubert GW, Smith Y, Levey AI, Conn PJ (2000). Activation of metabotropic glutamate receptor 5 has direct excitatory effects and potentiates NMDA receptor currents in neurons of the subthalamic nucleus. J Neurosci 20: 7871-7879.

Ayala JE, Chen Y, Banko JL, Sheffler DJ, Williams R, Telk AN et al (2009). mGluR5 positive allosteric modulators facilitate both hippocampal LTP and LTD and enhance spatial learning. Neuropsychopharmacology 34: 2057-2071.

Barker G, Warburton E (2008). NMDA receptor plasticity in the perirhinal and prefrontal cortices is crucial for the acquisition of long-term object-in-place associative memory. J Neurosci 28: 2837-2844.

Barker GR, Bashir ZI, Brown MW, Warburton EC (2006). A temporally distinct role for group I and group II metabotropic glutamate receptors in object recognition memory. Learning \& Memory 13: 178-186.

Barker GRI, Bird F, Alexander V, Warburton EC (2007). Recognition memory for objects, place, and temporal order: a disconnection analysis of the role of the medial prefrontal cortex and perirhinal cortex. J Neurosci 27: 2948-2957.

Barker GRI, Warburton EC, Koder T, Dolman NP, More JCA, Aggleton JP et al (2006). The different effects on recognition memory of perirhinal kainate and NMDA glutamate receptor antagonism: implications for underlying plasticity mechanisms. J Neurosci 26: 3561-3566.

Belcher A, O'dell S, Marshall J (2005). Impaired object recognition memory following methamphetamine, but not p-chloroamphetamine- or d-amphetamine-induced neurotoxicity. Neuropsychopharmacology 30: 2026-2034.

Belcher AM, O'Dell SJ, Marshall JF (2006). A sensitizing regimen of methamphetamine causes impairments in a novelty perference task of object recognition. Behav Brain Res 170: 167-172.

Belcher AM, Feinstein EM, O'Dell SJ, Marshall JF (2008). Methamphetamine influences on recognition memory: comparison of escalating and single-day dosing regimens. Neuropsychopharmacology 33: 1453-1463.

Berlyne DE (1950). Novelty and curiosity as determinants of exploratory behavior. Br J Psychol 41: 68-80.

Bevins RA, Besheer J, Palmatier MI, Jensen HC, Pickett KS, Eurek S (2002). Novel-object place conditioning: behavioral and dopaminergic processes in expression of novelty reward. Behav Brain Res 129: 41-50. 
Bisagno V, Ferguson D, Luine VN (2002). Short toxic methamphetamine schedule impairs object recognition task in male rats. Brain Res 940: 95-101.

Bortolato M, Frau R, Bini V, Luesu W, Loriga R, Collu M et al (2010). Methamphetamine neurotoxicity increases brain expression and alters behavioral functions of $\mathrm{CB}$ cannabinoid receptors. J Psychiatr Res (in press).

Briand LA, Gross JP, Robinson TE (2008). Impaired object recognition following prolonged withdrawal from extendedaccess cocaine self-administration. Neuroscience 155: 1-6.

Brown MW, Aggleton JP (2001). Recognition memory: what are the roles of the perirhinal cortex and hippocampus? Nat Rev Neurosci 2: 51-61.

Chang L, Alicata D, Ernst T, Volkow N (2007). Structural and metabolic brain changes in the striatum associated with methamphetamine abuse. Addiction 102(Suppl 1): 16-32.

Cho K, Kemp N, Noel J, Aggleton JP, Brown MW, Bashir ZI (2000). A new form of long-term depression in the perirhinal cortex. Nat Neurosci 3: 150-156.

Christoffersen GRJ, Simonyi A, Schachtman TR, Clausen B, Clement D, Bjerre VK et al (2008). MGlu5 antagonism impairs exploration and memory of spatial and non-spatial stimuli in rats. Behav Brain Res 191: 235-245.

Christopoulos A (2002). Allosteric binding sites on cell-surface receptors: novel targets for drug discovery. Nat Rev Drug Discov 1: 198-210.

Copani A, Romano C, Di Giorgi Gerevini V, Nicosia A, Casabona G, Storto $\mathrm{M}$ et al (2000). Reducing conditions differentially affect the functional and structural properties of group-I and -II metabotropic glutamate receptors. Brain Res 867: 165-172.

Darrah JM, Stefani MR, Moghaddam B (2008). Interaction of Nmethyl-D-aspartate and group 5 metabotropic glutamate receptors on behavioral flexibility using a novel operant set-shift paradigm. Behav Pharmacol 19: 225-234.

Ennaceur A (2010). One-trial object recognition in rats and mice: methodological and theoretical issues. Behav Brain Res 215: 244-254.

Ennaceur A, Aggleton JP (1997). The effects of neurotoxic lesions of the perirhinal cortex combined to fornix transection on object recognition memory in the rat. Behav Brain Res 88: 181-193.

Ennaceur A, Delacour J (1988). A new one-trial test for neurobiological studies of memory in rats. 1: behavioral data. Behav Brain Res 31: 47-59.

Ennaceur A, Neave N, Aggleton JP (1997). Spontaneous object recognition and object location memory in rats: the effects of lesions in the cingulate cortices, the medial prefrontal cortex, the cingulum bundle and the fornix. Exp Brain Res 113: 509-519.

Ernst T, Chang L (2008). Adaptation of brain glutamate plus glutamine during abstinence from chronic methamphetamine use. J Neuroimmune Pharmacol 3: 165-172.

Gass JT, Olive MF (2009). Positive allosteric modulation of mGluR5 receptors facilitates extinction of a cocaine contextual memory. Biol Psychiatry 65: 717-720.

Ghasemzadeh MB, Mueller C, Vasudevan P (2009). Behavioral sensitization to cocaine is associated with increased glutamate receptor trafficking to the postsynaptic density after extended withdrawal period. Neuroscience 159: 414-426.

Gonzalez R, Bechara A, Martin EM (2007). Executive functions among individuals with methamphetamine or alcohol as drugs of choice: preliminary observations. J Clin Exp Neuropsychol 29: 155-159.

Grimm JW, Lu L, Hayashi T, Hope BT, Su T-P, Shaham Y (2003). Time-dependent increases in brain-derived neurotrophic factor protein levels within the mesolimbic dopamine system after withdrawal from cocaine: Implications for incubation of cocaine craving. J Neurosci 23: 742-747.

Hoffman W, Moore M, Templin R, Mcfarland B, Hitzemann R, Mitchell S (2006). Neuropsychological function and delay discounting in methamphetamine-dependent individuals. Psychopharmacology 188: 162-170.

Kinney GG, O'Brien JA, Lemaire W, Burno M, Bickel DJ, Clements MK et al (2005). A novel selective positive allosteric modulator of metabotropic glutamate receptor subtype 5 has in vivo activity and antipsychotic-like effects in rat behavioral models. J Pharmacol Exp Ther 313: 199-206.

Kitamura O, Wee S, Specio SE, Koob GF, Pulvirenti L (2006). Escalation of methamphetamine self-administration in rats: a dose-effect function. Psychopharmacology 186: 48-53.

Krasnova IN, Justinova Z, Ladenheim B, Jayanthi S, McCoy MT, Barnes C et al (2010). Methamphetamine self-administration is associated with persistent biochemical alterations in striatal and cortical dopaminergic terminals in the rat. PLOS ONE 5: e8790.

Liu F, Grauer S, Kelley C, Navarra R, Graf R, Zhang G et al (2008). ADX47273 [S-(4-fluoro-phenyl)-\{3-[3-(4-fluoro-phenyl)[1,2,4]-oxadiazol-5-yl]-piperidin-1-yl\}-methanone]: a novel metabotropic glutamate receptor. J Pharmacol Exp Ther 327: 827-839.

Mandyam C, Wee S, Eisch A, Richardson H, Koob G (2007). Methamphetamine self-administration and voluntary exercise have opposing effects on medial prefrontal cortex gliogenesis. J Neurosci 27: 11442-11450.

Massey PV, Bashir ZI (2007). Long-term depression: multiple forms and implications for brain function. Trends Neurosci 30: 176-184.

Mitchell JB, Laiacona J (1998). The medial frontal cortex and temporal memory: tests using spontaneous exploratory behaviour in the rat. Behav Brain Res 97: 107-113.

Moussawi K, Pacchioni A, Moran M, Olive MF, Gass JT, Lavin A et al (2009). N-Acetylcysteine reverses cocaine-induced metaplasticity. Nat Neurosci 12: 182-189.

Mumby DG (2001). Perspectives on object-recognition memory following hippocampal damage: lessons from studies in rats. Behav Brain Res 127: 159-181.

Olive MF (2010). Cognitive effects of group I metabotropic glutamate receptor ligands in the context of drug addiction. Eur J Pharmacol 639: 47-58.

Paulus MP, Hozack N, Frank L, Brown GG, Schuckit MA (2003). Decision making by methamphetamine-dependent subjects is associated with error-rate-independent decrease in prefrontal and parietal activation. Biol Psychiatry 53: 65-74.

Pin J-P, Galvez T, Prézeau L (2003). Evolution, structure, and activation mechanism of family 3/C G-protein-coupled receptors. Pharmacol Ther 98: 325-354.

Rendell PG, Mazur M, Henry JD (2009). Prospective memory impairment in former users of methamphetamine. Psychopharmacology 203: 609-616.

Rogers J, Santis S, See R (2008). Extended methamphetamine selfadministration enhances reinstatement of drug seeking and impairs novel object recognition in rats. Psychopharmacology 199: 615-624.

Schröder N, O’Dell SJ, Marshall JF (2003). Neurotoxic methamphetamine regimen severely impairs recognition memory in rats. Synapse 49: 89-96.

Salo R, Nordahl TE, Galloway GP, Moore CD, Waters C, Leamon MH (2009). Drug abstinence and cognitive control in methamphetaminedependent individuals. J Subst Abuse Treat 37: 292-297.

Salo R, Nordahl TE, Natsuaki Y, Leamon MH, Galloway GP, Waters $\mathrm{C}$ et al (2007). Attentional control and brain metabolite levels in methamphetamine abusers. Biol Psychiatry 61: 1272-1280.

Salt TE, Binns KE (2000). Contributions of mGlu1 and mGlu5 receptors to interactions with $\mathrm{N}$-methyl-aspartate receptormediated responses and nociceptive sensory responses of rat thalamic neurons. Neuroscience 100: 375-380.

Schwendt M, Rocha A, See R, Pacchioni A, Mcginty J, Kalivas P (2009). Extended methamphetamine self-administration in rats results in a selective reduction of dopamine transporter levels in the prefrontal cortex and dorsal striatum not accompanied 
by marked monoaminergic depletion. J Pharmacol Exp Ther 331: 555.

Scott JC, Woods SP, Matt GE, Meyer RA, Heaton RK, Atkinson JH et al (2007). Neurocognitive effects of methamphetamine: a critical review and meta-analysis. Neuropsychol Rev 17: 275-297.

Sekine Y, Ouchi Y, Sugihara G, Takei N, Yoshikawa E, Nakamura K et al (2008). Methamphetamine causes microglial activation in the brains of human abusers. J Neurosci 28: 5756-5761.

Simon SL, Dacey J, Glynn S, Rawson R, Ling W (2004). The effect of relapse on cognition in abstinent methamphetamine abusers. J Subst Abuse Treat 27: 59-66.

Stefani MR, Moghaddam B (2010). Activation of type 5 metabotropic glutamate receptors attenuates deficits in cognitive flexibility induced by NMDA receptor blockade. Eur J Pharmacol 639: 26-32.

Tran-Nguyen LTL, Fuchs RA, Coffey GP, Baker DA, O'Dell LE, Neisewander JL (1998). Time-dependent changes in cocaineseeking behavior and extracellular dopamine levels in the amygdala during cocaine withdrawal. Neuropsychopharmacology 19: 48-59.

Uslaner JM, Parmentier-Batteur S, Flick RB, Surles NO, Lam JSH, McNaughton $\mathrm{CH}$ et al (2009). Dose-dependent effect of CDPPB, the mGluR5 positive allosteric modulator, on recognition memory is associated with GluR1 and CREB phosphorylation in the prefrontal cortex and hippocampus. Neuropharmacology 57: 531-538.
Volkow ND, Chang L, Wang G-J, Fowler JS, Franceschi D, Sedler M et al (2001a). Loss of dopamine transporters in methamphetamine abusers recovers with protracted abstinence. J Neurosci 21: 9414-9418.

Volkow ND, Chang L, Wang GJ, Fowler JS, Leonido-Yee M, Franceschi D et al (2001b). Association of dopamine transporter reduction with psychomotor impairment in methamphetamine abusers. Am J Psychiatry 158: 377-382.

Wan H, Aggleton JP, Brown MW (1999). Different contributions of the hippocampus and perirhinal cortex to recognition memory. J Neurosci 19: 1142-1148.

Warburton EC, Brown MW (2010). Findings from animals concerning when interactions between perirhinal cortex, hippocampus and medial prefrontal cortex are necessary for recognition memory. Neuropsychologia 48: 2262-2272.

Winters BD, Bussey TJ (2005). Glutamate receptors in perirhinal cortex mediate encoding, retrieval, and consolidation of object recognition memory. J Neurosci 25: 4243-4251.

Winters BD, Forwood SE, Cowell RA, Saksida LM, Bussey TJ (2004). Double dissociation between the effects of peripostrhinal cortex and hippocampal lesions on tests of object recognition and spatial memory: Heterogeneity of function within the temporal lobe. J Neurosci 24: 5901-5908.

Zhu XO, Brown MW, McCabe BJ, Aggleton JP (1995). Effects of the novelty or familiarity of visual stimuli on the expression of the immediate early gene c-fos in rat brain. Neuroscience 69: 821-829.

Supplementary Information accompanies the paper on the Neuropsychopharmacology website (http://www.nature.com/npp) 